\title{
Compact Wireless Access Nodes for WDM Bidirectional Radio-over-Fiber System Based on RSOA
}

\author{
Yu, Xianbin; Gibbon, Timothy Braidwood; Tafur Monroy, Idelfonso
}

Published in:

Conference proceedings, OFC

Publication date:

2009

Document Version

Publisher's PDF, also known as Version of record

Link back to DTU Orbit

Citation (APA):

Yu, X., Gibbon, T. B., \& Tafur Monroy, I. (2009). Compact Wireless Access Nodes for WDM Bidirectional Radioover-Fiber System Based on RSOA. In Conference proceedings, OFC (pp. 1-3). IEEE.

\section{General rights}

Copyright and moral rights for the publications made accessible in the public portal are retained by the authors and/or other copyright owners and it is a condition of accessing publications that users recognise and abide by the legal requirements associated with these rights.

- Users may download and print one copy of any publication from the public portal for the purpose of private study or research.

- You may not further distribute the material or use it for any profit-making activity or commercial gain

- You may freely distribute the URL identifying the publication in the public portal

If you believe that this document breaches copyright please contact us providing details, and we will remove access to the work immediately and investigate your claim. 


\title{
Compact Wireless Access Nodes for WDM Bidirectional Radio-over-Fiber System Based on RSOA
}

\author{
Xianbin Yu, T. B. Gibbon, I. Tafur Monroy \\ DTU Fotonik, Department of Photonics Engineering, Technical University of Denmark, DK-2800 Kgs. Lygnby, Denmark. \\ Tel: +45 452537 96, Fax: +45 459365 81, E-mail: xiyu@fotonik.dtu.dk
}

\begin{abstract}
We demonstrate a RSOA based WDM radio-over-fiber, bidirectional system for wireless access networks. The multi-functionalities of a RSOA, such as colorless operation, re-modulation and envelope detection, make wireless access nodes more compact. (C)2008 Optical Society of America

OCIS codes: (060.5625) Radio frequency photonics, (060.4258) networks, network topology
\end{abstract}

\section{Introduction}

Radio-over-Fiber (RoF) technology is very attractive for implementing seamless wireless access services in future networks, which is to consolidate different types of services into a homogenous infrastructure with compact network size and less connection complexity [1]. Traditionally, expensive radio-frequency (RF) down-conversion technology is necessary in the RoF transmission system. A more cost-effective RoF communication system with simple access nodes is therefore expected, as well as symmetric broadband wireless services. Recent research has shown that optical envelope detection techniques, without RF oscillator and mixer, satisfactorily perform reception of RoF signals [2,3]. On the other hand, reflective semiconductor optical amplifier (RSOA) operating as a modulator at an optical network unit (ONU) is a promising component to implement a bidirectional system because of its attractive features related to its multi-functionalities of optical amplifier and modulator [4-6]. Very recently, we have also proposed a bidirectional RoF system with phase modulation uplink and oscillator-free downlink by employing an RSOA, which acts simultaneously as an intensity modulator and an optical envelope detector [7]. In this paper, we exploit and evaluate the extension of the system performance, by using the colorless operation of the RSOA to build effective, bidirectional, wavelength division multiplexing (WDM) system with high wavelength utilization and improved capacity.

Fig. 1 depicts the network topology of WDM RoF wireless access networks by employing RSOAs. A central office is composed of a laser array with $n$ laserliodes (LDs) which offers WDM wavelengths for downlink, a receiver array to demodulate uplink signals from ONUs, a phase modulator (PM) array to impose electrical information into optical carrier signal, and two arrayed waveguide gratings (AWGs) operate as a wavelength multiplexer and a demultiplexer. A circulator is used to separate the WDM downstream transmitters and upstream channels. At the remote node after fiber transmission, another AWG is employed to separate the WDM downstream channels and combine the upstream channels. Each ONU includes a downstream receiver and a RSOA.

In this paper we experimentally demonstrate a RSOA based WDM bidirectional RoF transmission system. The multi-functionalities of RSOA, such as colorless operation, re-modulation and envelope detection, lead to no need of RF down-conversion and laser source for the uplink, and make the wireless access nodes simple and compact.

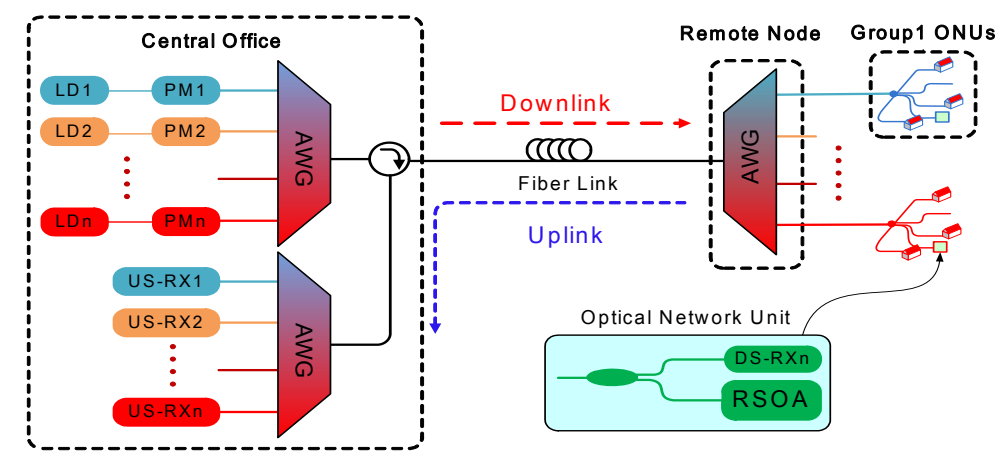

Fig. 1. Schematic diagram of WDM bidirectional wireless access networks. LD: laserdiode, PM: phase modulator, AWG: arrayed waveguide grating, US-RX $n$ : $n$th channel upstream receiver, DS-RXn: $n$th channel downstream receiver, RSOA: reflective semiconductor optical amplifier. 


\section{OWP1.pdf}

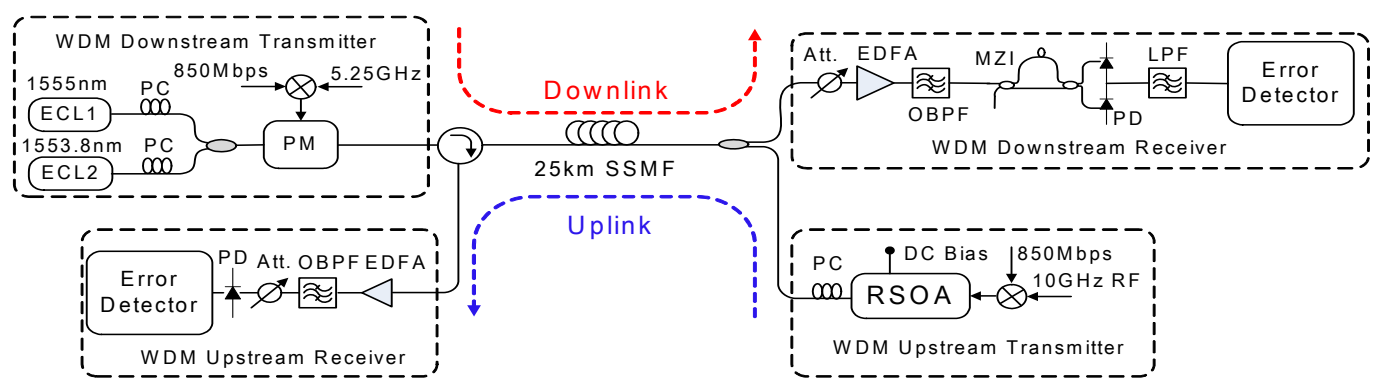

Fig. 2. The experimental setup of a two-channel bidirectional RoF system .

\section{Experimental Setup and Operation Principle}

The proof-of-concept experimental setup is shown in Fig. 2. Two lights from two external cavity lasers (ECL1 and ECL2) with wavelengths of $1555 \mathrm{~nm}$ and $1553.8 \mathrm{~nm}$ are combined at a $3 \mathrm{~dB}$ coupler, and then phase modulated at $5.25 \mathrm{GHz}$ RF carrying $850 \mathrm{Mbps}$ data with pseudo random binary sequence (PRBS) length of $2^{9}-1$. The optical spectra for downstream signals after the phase modulator is shown in Fig.3 (a), and we state that channel 1 (Ch1) is at $1555 \mathrm{~nm}$ wavelength, and channel $2(\mathrm{Ch} 2)$ is at $1553.8 \mathrm{~nm}$. This two-channel downstream signal is launched into $25 \mathrm{~km}$ of standard single mode fiber (SSMF) with a $5 \mathrm{~dB}$ insertion loss. At the output of the fiber, another $3 \mathrm{~dB}$ coupler is used to split the downstream signals. Half the signals proceed to the downstream receiver, and the other half are routed to the RSOA at upstream transmitter for wavelengths reuse as the upstream signals. At the downstream receivers the optical signals are amplified by an Er-doped fiber amplifier (EDFA) and the EDFA noise is rejected using an optical bandpass filter with a $3 \mathrm{~dB}$ bandwidth of $0.4 \mathrm{~nm}$. An imbalanced-path Mach-Zehnder interferometer (MZI) performs the function of optical self-heterodyning to translate the phase encoded information to intensity information. A MZI with a frequency response period of $10.7 \mathrm{GHz}$ is used in the experiment. After balanced photodetection, the signal is down-converted by using a $1.8 \mathrm{GHz}$ electrical lowpass filter (LPF) and is subsequently fed to an error detector for bit error rate (BER) measurements on the downstream signal. By tuning the phase offset between the two arms of the MZI, the signal after photodetection is composed of both a down-converted baseband component and higher order frequency components containing the complete RoF signal [9]. At the upstream transmitter, a $10 \mathrm{GHz}$ RF signal carrying $850 \mathrm{Mbps}$ data with length of $2^{9}-1$ is used to drive the RSOA biased at 1.4 V DC. Lights from the phase modulated downlink signals are intensity modulated and reflected by the RSOA, therefore the downstream and upstream channels share the same wavelength and optical source. The reflective upstream signals are then transmitted in the reverse direction over $25 \mathrm{~km}$ of SSMF and detected by an upstream receiver, which consists of an EDFA, an optical bandpass filter (OBPF), an attenuator and a photodiode.

In this system, the RSOA firstly performs high-wave rectidificaion by the choice of the bias. Secondly, due to the modulation speed limitation it performs simultaneously the envelope detection (allows only the baseband frequency components within the electrical bandwidth of RSOA). As shown in Fig. 3 (b), when the 850 Mbps bit rate at $10 \mathrm{GHz}$ RF is applied to RSOA (1.5 GHz bandwidth), no RF components are observed on a scope detecting the reflective optical signal, and only the $850 \mathrm{Mbps}$ digital signal is recovered. The RSOA therefore performs not only the function of optical intensity modulator, but also the function of envelope detection, which leads to no need of microwave components, such as RF mixer and local oscillator.

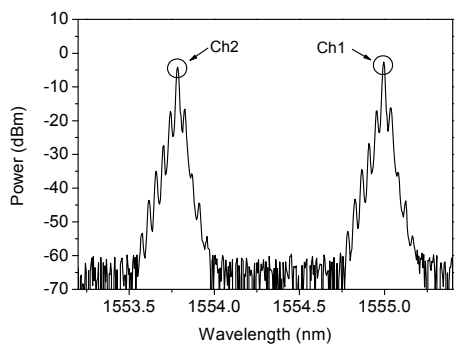

(a)

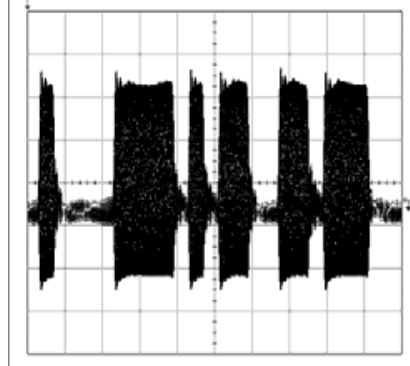

(b)

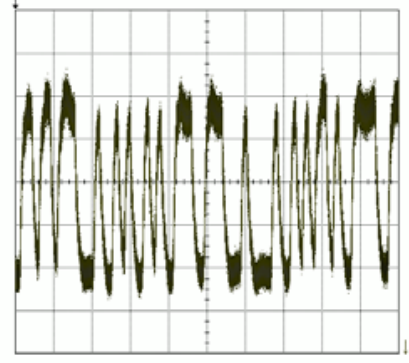

(c)

Fig. 3. (a) The optical spectra after phase modulator. Channel 1 (Ch1): $1555 \mathrm{~nm}$, Channel 2 (Ch2): $1553.8 \mathrm{~nm}$. (b) The electrical $10 \mathrm{GHz}$ RF carrying $850 \mathrm{Mbps}$ data driving the RSOA at the upstream transmitter, Horizontal scale: $2 \mathrm{~ns} / \mathrm{div}$, Vertical scale: $560 \mathrm{mV} /$ div. (c) The recovered electrical signal on a scope from driving signal (a) Horizontal scale: $5 \mathrm{~ns} / \mathrm{div}$, Vertical scale: $56 \mathrm{~mW} / \mathrm{div}$. 


\section{OWP1.pdf}

\section{Experimental Results and Discussions}

The BER curves for both downstream channels are displayed in Fig.4 (a). All the cases are measured after $25 \mathrm{~km}$ fiber transmission with the co-propagation of upstream signals. The results indicate that the $\mathrm{Ch} 1 \mathrm{downstream}$ receiver sensitivities at a BER of $10^{-9}$ are around $-24.5 \mathrm{dBm}$ and $-21.5 \mathrm{dBm}$ for the cases with and without $\mathrm{Ch} 2$ downstream signals, respectively. For the $\mathrm{Ch} 2$ downstream signals, the downstream receiver sensitivities with and without the co-propagation of $\mathrm{Ch} 1$ are found to be about $-23.0 \mathrm{dBm}$ and $-20 . \mathrm{dBm}$. Fig.4 (b) shows the measured BER performances for 2-channel upstream signals after $25 \mathrm{~km} \mathrm{SSMF} \mathrm{transmission,} \mathrm{as} \mathrm{well} \mathrm{as} \mathrm{with} \mathrm{and} \mathrm{without} \mathrm{the}$ co-propagation of the neighbor channel. We can notice from Fig.4 (b) that when two channels are transmitted simultaneously, both channels ( $\mathrm{Ch} 1$ and $\mathrm{Ch} 2$ ) have same receiver sensitivities of $-12 \mathrm{dBm}$. In the cases of one-channel transmission, the receiver sensitivities for $\mathrm{Ch} 1$ and $\mathrm{Ch} 2$ are about $14 \mathrm{dBm}$ and $-15 \mathrm{dBm}$, respectively.

For either downstream or upstream channels, we can notice that the co-propagation of second channel introduces about $3 \mathrm{~dB}$ sensitivity penalty. Limited by the $18 \mathrm{~dB}$ rejection of OBPF at $1.2 \mathrm{~nm}$ bandwidth, the crosstalk caused by the Rayleigh backscattering from the neighbor channel degrades the receiver sensitivity [8]. On the other hand, the performances of the upstream signals are also related to the gain and noise figure of the RSOA. Actually, the RSOA used in the experiment performs the functions of not only an intensity modulator and an envelope detector, but also an optical amplifier. The amplified spontaneous emission (ASE) noise decreases the signal-to-noise ratio of the upstream signal. As shown the inserted eye diagrams in Fig.4, the eye diagram of downstream signal is cleaner than that the upstream signal.

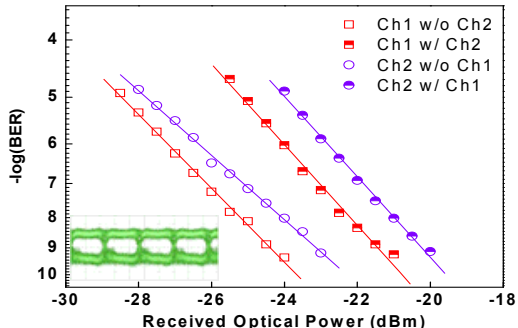

(a)

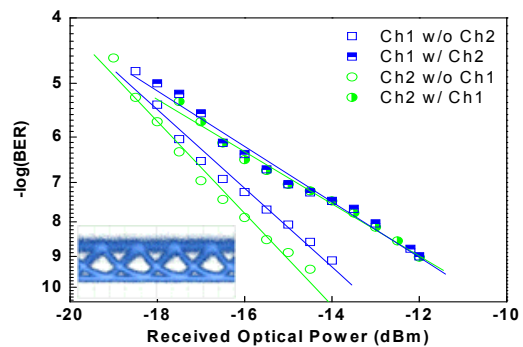

(b)

Fig. 4. The measured BER curves of two-channel (a) downstream and (b) upstream RoF signals after $25 \mathrm{~km}$ fiber transmission.

\section{Conclusions}

We propose and experimentally demonstrate a WDM bidirectional RoF network with compact wireless access nodes. Contributed to the multi-functionalities of RSOA, no laser source and RF down conversion are needed for the uplinks. In the experiment, in order to separate the transmitted RoF signals at the same wavelength, phase modulation and intensity modulation are used for downstream and upstream signals, respectively. The experimental results show that all channels for both $850 \mathrm{Mbps}$ at $10 \mathrm{GHz} \mathrm{RF}$ upstream and $850 \mathrm{Mbps}$ at $5.25 \mathrm{GHz} \mathrm{RF}$ downstream signals are error-free after $25 \mathrm{~km}$ SSMF transmission. Therefore, the proposed system offers a good solution for next generation optical wireless access network.

\section{References}

[1] J. Campany, D. Novak, "Microwave photonics combines two worlds", Nature Photonics, vol. 1, June 2007, pp. 319-330.

[2] J. Seoane, I. T. Monroy, K. Prince, P. Jeppesen, "Local oscillator free wireless-optical-wireless data link at $1.25 \mathrm{Gbit} / \mathrm{s}$ over a $40 \mathrm{GHz}$ carrier employing carrier preservation and envelope detection", Conference on Optical Fiber Communication 2008, 24-28, pp.1-3.

[3] K. Prince, I. T. Monroy, "Converged fixed and radio-over-fiber link employing optical envelope detection and optically injected DFB laser", Conference on Optical Fiber Communication 2008, Paper OThD7.

[4] J. Prat, C. Arellano, V. Polo, and C. Bock, "Optical network unit based on a bidirectional reflective semiconductor optical amplifier for fiber-to-the-home networks", IEEE Photon. Technol. Lett., vol. 17, no. 1, 2005, pp. 250-252.

[5] M. D. Feuer, J. M. Wiesenfeld, J. S. Perino, C. A. Burrus, G. Raybon, S. C. Shunk, and N. K. Dutta, "Single-port laser-amplifier modulators for local access," IEEE Photon. Technol. Lett., vol. 8, no. 9, Sep. 1996, pp. 1175-1177.

[6] N. Buldawoo, S. Mottet, F. Le Gall, D. Sigonge, D. Meichenin, and S. Chelles, "A semiconductor laser amplifier-reflector for the future FTTH applications," in Proc. Eur. Conf. Opt. Commun. (ECOC 1997), Edinburgh, U.K., pp. 196-199.

[7] X. Yu, T. B. Gibbon, I. T. Monroy, "Bidirectional radio-over-fiber system with phase modulation downlink and RF oscillator-free uplink using a reflective SOA", IEEE Photon. Technol. Lett., submitted for publication.

[8] J. Ko, S. Kim, J. Lee, S. Won, Y. S. Kim, and J. Jeong, "Estimation of performance degradation of bidirectional WDM transmission systems due to Rayleigh backscattering and ASE noises using numerical and analytical models," J. Lightw. Technol., vol. 21, no. 4, pp. 938-946, Apr. 2003.

[9] X. Yu, T. B. Gibbon, I. T. Monroy, "Converged wireless and wireline access system based on optical phase modulation for both radio-over-fiber and baseband signals", IEEE Photon. Technol. Lett., to be published. 